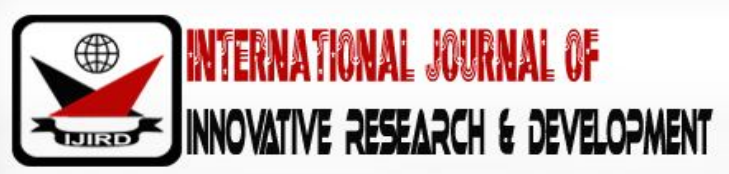

ISSN 2278 - 0211 (Online)

\section{A Sociolinguistic Analysis of the Perceptions of Students in a Ghanaian University, on the Use of First Person Pronouns in Academic Writing}

\author{
Wilhelmina Coker Annan \\ Tutor, Department of Languages (English Language Studies), OLA College of Education, Ghana
}

\begin{abstract}
:
This study presents the perceptions of students on the use of first person pronouns in academic writing as well as the gender group which makes use of it most in their academic writing. Questionnaires were therefore administered to forty students; twenty males and twenty female, in the faculty of Arts of the University of Cape Coast, Ghana for a case study. The data revealed that students are gradually moving away from the traditional of being objective and not being explicit about personal views in academic writing. They are rather adapting to the new way of being explicit in claiming their stance in academic writing through the use of FPPs. The data also showed that female students use first person pronouns in their academic writing more than male students. These findings thus have implications of orienting students towards the use of first person pronouns in their academic writings to help them represent themselves in their work and to show ownership as well.
\end{abstract}

Kevwords: Perception, gender, first person pronouns, academic writing

\section{Introduction}

In an attempt to avoid repetition in both spoken and written discourse, pronouns are used to substitute nouns. Agreeing in both number (singular and plural) and gender (masculine and feminine) with their subjects (noun) that has already been mentioned in the discourse, English pronouns indicate the differences in persons (first, second and third) as well. In their discussion on pronouns, Quirk and Greenbaum (2000) outline five features of English pronouns. According to them, English pronouns do not only have two cases: common and genitive, but they have an objective case, person distinction and overt gender contrast. However, they are not morphologically related and do not admit determiners.

First person pronouns (I, we, me, us) as a type of English pronouns are used to either refer to the speaker, the listener or the subject under discussion that has already been mentioned in the discourse for the sake of cohesion and coherence, hence acquiring the name personal. Having two sets of case - forms: subjective forms and objective forms, the first person pronouns (henceforth FPPs) only do not function either as subjects or objects of finite verbs, but they also operate as either subject or as prepositional complements and are also replacements for co-referential noun phrases in neighbouring (usually preceding) clauses (Quirk \& Greenbaum, 2000, p. 103).

Traditionally, writers in the academia are required to present their views and facts without being explicit about their positions. They are therefore expected to detach and distant themselves from their academic writings. On the contrary, Hyland, (2005) asserts that over the last decades, there have been some changes in academic writing to the extent that writers are now subjective, explicit and personal in their academic writing. Obviously, this new development that Hyland talks about is evident in the way scholars in the academia currently resort to the use of the FPPs as tools in reporting their empirical studies for numerous reasons. Among some of these reasons are to either refer to themselves as the owner of the work or to make claims. Scholars also use the FPPs to show authorial stance on issues and to establish some level of interaction with their readers. (Tang \& John, 1999; Hyland, 2002; Harwood, 2005; Hyland, 2005).

This paradigm shift by experts in the academia has resulted in students adopting this style of writing into their academic writing. It has been observed that students are gradually moving from the traditional way of academic writing to the frequent use of the FPPs because of the kind of texts and articles they encounter during their academic work (Tang \& John, 1999; Hyland, 2002). Writers of such articles and texts in the students' area of study tend to be more assertive and concrete in making claims through the use of FPPs and as such students are exposed to such style of writing. Henderson and Barr (2010) share in this view that students can become more aware of some of the language used to express authorial stance from the texts they read. For instance, Hyland (2002) requires that writers should establish a stance towards their propositions, to get 
behind their words and stake out a position. Such exposure to these academic texts is believed to even go a long way, to help them acquire the skill of writing, for them to be recognized as part of the discourse community they wish to belong, as defined by Swales (1990).

As a social variable, gender has also for long been an essential phenomenon that always exists alongside other variables (race, ethnicity, social class, age and social status) in the society. Nonetheless, many questions have been asked about the differences between males and females in relation to the use of language. Consequently, many sociolinguists have therefore made several attempts, to establish such differences between males and females in the society, especially in the use of language to communicate (Herring, 1993; Brownlow et al, 2003; Colley et al., 2004;). Conversely, some researchers also contest to this same phenomenon of gender differences in language use that, there are no differences between males and females in terms of language use and writing, especially in formal situations (Yazdani \& Samar, 2010; Berryman-Fink \& Wilcox, 1983; Simkins-Bullock \& Wildman, 1999; Argamon, S. et al, 2003).

The literature on the use of the FPPs in academic writing shows that, the focus of scholars in this terrain has been on how writers or researchers, both experts and students present themselves in their empirical research works, to their readers in the academia through the use of the FPPs. Since students are gradually moving towards the use of the FPPs in their academic writing, it is my quest to add to this body of literature on the use of the FPPs by writers in the academia, by finding out students' perceptions on the use of the FPPs in academic writing. This interest is germane because, even Taki (2012), confirms that researchers in this field have increasingly investigated the ways in which writers and speakers project their personal feelings and judgments in what they produce. Thus specifically, this study is to find out the perceptions of students in a Ghanaian University, on the use of the first person pronouns in academic writing. The trajectory of the analysis will be along the sociolinguistic variable of gender (male and female students), looking at their differences in relation to students' use of FPPS in academic writing. Therefore, to achieve this feat, the following research questions guided the study.

- What do undergraduate students in a Ghanaian University think of the use of first person pronoun in academic writing?

- Which gender group of students mostly makes use of the first person pronoun in their academic writing?

\section{Materials and Methods}

This rhetorical unit captures the type of research adopted, the research instruments used in gathering the data as well as the analysis of the data collected. Essentially, the case study approach was used. Although many critics believe that the case study approach is not robust enough to make meaningful generalizations, Zainal (2007), on the contrary, asserts that the detailed qualitative accounts often produced in case studies not only help to explore or describe the data in real-life environment, but also help to explain the complexities of real life situations which may not be captured through experimental or survey research (p.4). Yin (1984) also proves that the case study is "an empirical inquiry that investigates a contemporary phenomenon within its real-life context; when the boundaries between phenomenon and context are not clearly evident; and in which multiple sources of evidence are used" (p. 23). Therefore, conducting a case study into the perceptions of students on the use of the FPPs in their academic writing, as it has been identified as a new phenomenon in the academia, is in the right direction.

Hence, the research instrument used in gathering data was the questionnaire. Questionnaires were used because, as it ensures quick collection of data in the shortest possible time, it also helps to analyze data objectively away from the researcher's beliefs and ideologies. Data was collected within five days at the faculty of Arts of the University of Cape Coast, Ghana. The Faculty of Arts of the University of Cape Coast was chosen as the research site due to proximity to the researcher, who was a student in this university and a member of the faculty of Arts. The questionnaire used, had two sections. While section A sought for the age, level, gender and department of the respondent, section B asked open ended questions directed to find out the perceptions of the respondents on the use of the FPPs in their academic writing. It also sought to find out whether males use the FPPs in their academic writing than their female counterparts or otherwise. Before the questionnaires were administered, the sociolinguistics course instructor examined and endorsed the authenticity of the questionnaire for the sake of validity and reliability.

Purposively, the questionnaires were administered to forty undergraduate students in the faculty: twenty males and twenty females. For the undergraduates, questionnaires were distributed to ten students in each of the levels (100 to 400); five for each gender group in the faculty of Arts. Data was collected from these subjects in order to be able to find out students' perception on the use of the FPPs in academic writing in terms of gender (males and females students).

The data collected were then labeled as MP (Male Perception) and FP (Female Perception) before analyzing the responses provided by respondents in the open ended questionnaires using qualitative content analysis, complemented by a little of quantitative analysis. The choice of qualitative content analysis is on the basis that it will help reveal the various reasons for the use of FPPs by students and their perceptions on the use of the FPPs in academic writing in terms of gender. Fraenkel and Wallen (2000) teaches that a person's or group's conscious or unconscious beliefs, attitudes, values and ideas often are revealed in their communications through a rigorous content analysis. Moreover, the use of the qualitative content analysis also helped to bring out the differences between male and female students in terms of the use of FPPs. For inter-rater reliability, a colleague tutor of English Studies was also allowed to analyze the data and the percentage of reliability was ninety. 


\section{Results and Discussion}

This section presents the analysis of the data on the perception of the students, on the use of the FPPs in their academic writing. The section also captures the analysis of whether male students use the aforementioned pronouns in their academic writing more than females or otherwise.

\subsection{Students' Perception on the Use of Personal Pronouns}

In the data, it was revealed that twenty-four students which form $60 \%$ of the data set reported that, they make use of the FPPs in their academic writing, as opposed to $40 \%$ who denied the use of the FPPs in their academic writing. Twenty-six out of forty students also showed that they support students' use of the FPPs in their academic writing. This group forms $65 \%$ of the data set as against 35\% who do not support the use of FPPs by students in their academic writing. This is because; from their responses, some think that the FPPs are used in informal settings and so it renders an academic work informal, if they are used by students in their write ups. Some also admit that they refuse to use FPPs because they often make use of information from other sources in their writing and so they cannot personalize the work. The excerpts below are some students' responses to the question as to the reason why they make use of the FPPs or not.

...is an indicative of informality and therefore does not evince politeness...MP2

...most of the information I use in my writing are ideas from books and the net...FP3

Therefore, the $65 \%$ of the students who support students' use of FPPs in academic writing do not only do so, but they earnestly encourage their fellow students to use FPPs in their writing. Besides, the respondents support the use of FPPs because some of them trust that, it offers a platform for them to express their personal views and some also believe that it is a way of showing ownership of their work, yet others also responded that they support the use of FPPs because, they think that FPPs are good tools for them to state their claims. Below are some responses from the students.

So that their voice can be heard in the written piece... MP10

This will make students give a concrete evidence of any idea they want to put across...MP7

It gives the student the opportunity to freely express him/ herself with relation to the work that is being done...FP1

I think the views of students may add up to existing knowledge if they use the first person pronoun when expressing themselves...FP9

The numerous reasons that students gave for their use of FPPs in their academic writing as presented above is a substantiation of Cadman's (1997) findings on why writers make use of FPPs in their writing.

Nevertheless, twenty-four out of forty respondents guarantee that the use of FPPs is very important but six of the respondents have the idea that, it is unimportant for students to use the FPPs in their academic writing, even though the remaining ten out of the forty respondents are not sure whether the use of FPPs in students' academic writing is important or not. In addition, on the question of whether students avoid the use of FPPs in academic writing, eighteen respondents, confirm that recently students do not avoid the use of the FPPs in their academic writing as they previously did in the traditional way of academic writing. These respondents think that students are now adopting the use of FPPs in their academic writing to help them take stance, make claims and also to express their personal views in order to represent themselves in the work as their own.

with certain issues, students will be able to take a stance and the 'T' is important..FP9

this is because without the use of it, students will not be able to claim ownership of their

own work...MP4

In addition, though some respondents did not actually know whether students avoid the use of FPPs in their academic writing or not, eighteen students out of forty, on the contrary, think that students avoid the use of FPPs in their academic writing for the following reasons. Some believe that students ignore using the FPPs in order to avoid plagiarism, to detach themselves from the work or because they just do not have knowledge of the use of FPPs in academic work. Moreover others also think that some students avoid the use of FPPs because they do not claim ownership of the work they do, since they believe that they borrow ideas from other authorities to do their work and that examiners will not approve of the use of FPPs in presenting such borrowed ideas. Some even think that it is impolite on the path of students to make use of FPPs in academic writing. Examples are below.

Because they feel they have to present their information from an objective point of view...MP10

Because most of their ideas are from books and the internet...FP3

From the analysis so far, though students are now adopting and adapting to the use of FPPs in their academic writing, a closer look at the percentages pertaining to the issue of whether students today make use of the FPPs or not significantly reveals that the percentage of respondents who think students avoid the use of the FPPs is almost equal to the percentage of those who think that students do not avoid the FPPs in their academic writing. This clearly confirms the sense of ambivalence among students that Hyland (2002) cites in his work that, some textbooks and style guides advice students to avoid the use of personal intervention in their writing (Gong \& Dragga, 1995; Lester, 1993; Spencer \& Arbon, 1996; Arnaudet \& Barrett, 1984), other textbooks encourage the use of the personal intervention in their writing (Day, 1994; Swales \& Feak, 1994; (Mills \& Water, 1986). In such regard, it causes a sense of ambivalence among students on the use of the first person pronoun in their writing (p.1095). 


\subsection{Use of First Person Pronouns in Terms of Gender}

In terms of gender, five correspondents out of the twenty female respondents think that female students use FPPs most in their academic writing while three out of the twenty female respondents also think that the use of FPPs in academic writing is mostly done by male students. On the other hand, four out of twenty male respondents have the perception that FPPs are used mostly by female students and the same percentage of male respondents think that it is rather male students who make use of FPPs than female students. However, the remaining two of the male respondents and that of the female respondents were neutral as to which gender of students makes use of FPPs in academic writing.

In totality, $45 \%$ of the total number of both male and female respondents identifies that, female students make use of FPPs in their academic writing more than male students, as against the $35 \%$ who perceive that male students use FPPs than female students. The $45 \%$ claim that female students use FPPs in their academic writing more than male students because, a greater number of this percentage think that females are emotional and always want to sound personal. Some of them also think that females always want to be specific and claim ownership of what they have achieved.

...because of their emotive nature...they wanna be personal or attach themselves to their writing...MP2

females are more self-centered and write from intuition, which is kind of personal...MP1

because ladies always want everything to be about them and so they transfer that to their academic writing...FP8

they like to express themselves...FP9

As for the few respondents who perceive male students as most users of FPPs in their academic writing, believe that male students see themselves as knowledgeable and like to dominate. Just a few of them think that male students use FPPs to express themselves.

We try to always show that we know what we're doing...MP4

For domination...MP5

Because they think they know...FP5

Of course some authors have undeniably affirmed that there are no differences at all between male and female writing styles as regards writing in formal contexts (Berryman-Fink \& Wilcox, 1983; Simkins-Bullock \& Wildman, 1991), nevertheless, results of the above analysis, is in opposition to this affirmation. It points to the fact that at least, in the academia, there is a gender difference in terms of the use of FPPs by students in their academic writing. This is because students in the faculty of Arts of the University of Cape Coast, have confirmed that female students make use of FPPs in their academic writing more than their male counterparts.

Moreover, this finding is also in tandem with the findings of what Argamon, et al. (2003) studied on gender, genre, and writing style in formal written text. They found out in their analysis of the use of pronouns in fiction and nonfiction works that, pronoun use is overwhelmingly more female than male in both fiction and nonfiction.

\section{Conclusions}

Conclusively, this paper has explored the perceptions of undergraduate students on the use of pronouns in academic writing, as well as the gender group of students who make use of first person pronouns mostly in their academic writing. The analysis realized three outcomes. First, it indicates that students are gradually moving away from the traditional way of writing as shown in the analysis above and are adopting the use of the FPPs in their academic writing, which is as a result of the exposure to the way scholars make use of the FPPs recently in their research articles. It is seen that these students who support the use of FPPs, are not only making use of FPPs in their writing, they also strongly encourage their fellow students to make use of them in their academic writing as well.

Secondly, students have the perception that using FPPs in their academic writing is an important thing to do since it helps them to show ownership of the work they do, to identify themselves with and in their work and also to portray the active role they play in producing their academic papers. Furthermore, although students are adopting the use of FPPs in their writing, they have the perception that others still keep away from using FPPs for the avoidance of plagiarism, to distant themselves from the work as they were taught by their lecturers to do so or even for sheer ignorance of the use of FPPs in academic writing.

Finally, this study discloses that both male and female students perceive that female students make use of FPPs in their academic writing than their male counterparts. The female students admit this because they believe that females are emotive and they show attachment to everything they do. Male students rather think that female students use FPPs because naturally, females like to express themselves more than males and, therefore, transfer that to their writings.

Therefore, this study helps to orient other students towards the increasingly use of first person pronouns (FPPs) in academic writing. It will also inform students as to why their colleagues have chosen to make use of FPPs in their academic writing and hence encourage them to make use of them as well. This study is also significant because of its pedagogical implications. It may help to inform lectures and educational instructors about the new development in the way of writing in the academia and assist and equip their students to learn how to use them constructively.

\section{References}

i. Argamon, S. et al. (2003) Gender, Genre, and Writing Style in Formal Written Texts. Text Interdisciplinary Journal for the Study of Discourse, 23 (3), 321-346 
ii. Berryman-Fink, C. L., \& Wilcox, T. R. (1983). A multivariate investigation of perceptual attributions concerning gender appropriateness in language. Sex Roles, 9. Retrieved June, 2012 from: http:/ / Scholar.google.com.

iii. Brownlow, S., Rosamond, J., A., \& Parker, J., A. (2003). Gender-Linked Linguistic Behavior in Television Interviews. Retrieved June 2012 from: http:/ / Scholar.google.com.

iv. Cadman, K. (1997). Thesis writing for international students: a question of identity? English for Specific Purposes 16 (1), 3-14.

v. Colley, A. et al, (2004). Style and content in emails and letters to male and female friends. Journal of Language and Social Psychology, 23, 369-378.

vi. Fraenkel, J. R. and Wallen, N. E. (2000). How to design and evaluate research in education. $4^{\text {th }}$ Edn., Mc-Graw High School. New York.

vii. Harwood, N. (2005). Nowhere has anyone attempted ... In this article I aim to do just that' A corpus-based study of self-promotional I and we in academic writing across four disciplines Journal of Pragmatics 37, 1207-1231

viii. Henderson, A. \& Barr, R. (2010). Comparing indicators of authorial stance in psychology students' writing and published research articles. Journal of Writing Research 2, 245-264.

ix. Herring, S. C. (1993). Gender and democracy in computer-mediated communication. Retrieved June 2012 from: http:/ / Scholar.google.com.

x. Hyland, K. (2002). Authority and invisibility: Authorial identity in academic writing. Journal ofPragmatics 34, 1091112.

xi. Hyland, K. (2005). Representing readers in writing: Student and expert practices. Linguistics and Education, 16, 363377.

xii. Quirk, R. \& Greenbaum, S. (200). University Grammar of English. New Delhi: Addison Wesley Longman.

xiii. Simkins-Bullock, J. A., \& Wildman, B. G. (1991). An investigation into the relationship between gender and language. Sex Roles, 24. Retrieved June, 2009 from: http:/ / Scholar.google.com.

xiv. Swales, J. M. (1990). Genre Analysis: English in academic and research settings. Cambridge: Cambridge University Press.

xv. Taki, S. (2012) Engagement and stance in academic writing: A study of English and Persian research articles. Mediterranean Journal of Social Sciences Vol. 3 (1), 157-168

xvi. Tang, R. \& John, S. (1999). The 'T' identity: Exploring writer identity in student academic writing through the first person pronoun. English for Specific Purposes 18, S 23-S39.

xvii. Yazdani, P. \& Samar, R. G. (2010). Involved or Informative: A Gender Perspective on Using Pronouns and Specifiers in EFL Students' Writing. MJAL 2 (5), 354-378

xviii. Yin, R. K. (1984). Case study research: Design and methods. Newbury Park, CA: Sage

xix. Zainal, Z. (2007) Case study as a research method Jurnal Kemanusiaan bil.9, 1-6.

\section{Appendix}

\section{University of Cape Coast}

Department of English

Sociolinguistics

Perceptions of Students on the Use of First Person Pronoun in Academic Writing

Section A

Tick where appropriate

Male [ ] Female [ ]

Age ...................................

Level: $100[$ ] $\quad 200[$ ] $\quad 300[$ ] $\quad 400[$ ]

Department:

Section B

Tick where appropriate

Do you use the first person pronoun in your academic writing?

Yes [ ] No [ ] If Yes, why? If No, why?

Do you support the use of first person pronoun by students in their academic writing?
Yes [ ]
No [ ]
If Yes, why?
If No, why 
What is your reaction to the use of Personal Pronoun by students in academic writing?

Which of these groups of people make use of first person pronoun in academic writing?

Males [ ] $\quad$ Females [ ]

Give one reason for your choice above

Will you encourage your fellow students to use the first person pronoun in their academic writing?

Yes [ ] No [ ] If Yes, why? If No, why?

How important is the use of the first person pronoun in students' academic writing?

Not important [ ] Important [ ] Not sure [ ]

Does the student's use of the first person pronoun in his/ her academic writing show his/ her ownership of their work?

Yes [ ] No [ ]

Do students refuse to use first person pronouns in their academic writing?

Yes [ ] No [ ] Why?

FPPs - $\quad$ First Person Pronouns

MP - Male Perception

FP - Female Perception 